\title{
Deoxynivalenol, zearalenone, and Fusarium graminearum contamination of cereal straw; field distribution; and sampling of big bales
}

\author{
P. Häggblom • E. Nordkvist
}

Received: 14 November 2014 / Revised: 28 January 2015 / Accepted: 29 January 2015 /Published online: 11 February 2015

(C) The Author(s) 2015. This article is published with open access at Springerlink.com

\begin{abstract}
Sampling of straw bales from wheat, barley, and oats was carried out after harvest showing large variations in deoxynivalenol (DON) and zearalenone (ZEN) levels. In the wheat field, DON was detected in all straw samples with an average DON concentration of $976 \mu \mathrm{g} / \mathrm{kg}$ and a median of $525 \mu \mathrm{g} / \mathrm{kg}$, while in four bales, the concentrations were above $3000 \mu \mathrm{g} / \mathrm{kg}$. For ZEN, the concentrations were more uniform with an average concentration of $11 \mu \mathrm{g} / \mathrm{kg}$. The barley straw bales were all positive for DON with an average concentration of $449 \mu \mathrm{g} / \mathrm{kg}$ and three bales above $800 \mu \mathrm{g} / \mathrm{kg}$. In oat straw, the average DON concentration was $6719 \mu \mathrm{g} / \mathrm{kg}$ with the lowest concentration at $2614 \mu \mathrm{g} / \mathrm{kg}$ and eight samples above $8000 \mu \mathrm{g} / \mathrm{kg}$. ZEN contamination was detected in all bales with an average concentration of $53 \mu \mathrm{g} / \mathrm{kg}$ with the highest concentration at $219 \mu \mathrm{g} / \mathrm{kg}$. Oat bales from another field showed an average concentration of $16,382 \mu \mathrm{g} / \mathrm{kg}$. ZEN concentrations in the oat bales were on average $153 \mu \mathrm{g} / \mathrm{kg}$ with a maximum at $284 \mu \mathrm{g} / \mathrm{kg}$. Levels of Fusarium graminearum DNA were higher in oat straw (max 6444 pg DNA/mg straw) compared to straw from wheat or barley. The significance of mycotoxin exposure from straw should not be neglected particularly in years when high levels of DON and ZEN are also detected in the feed grain. With a limited number of samples preferably using a sampling probe, it is possible to distinguish lots of straw that should not be used as bedding material for pigs.
\end{abstract}

Keywords Mycotoxin · Straw · Cereal · Sampling · Fusarium $\cdot$ DON $\cdot$ ZEN

P. Häggblom $(\bowtie) \cdot$ E. Nordkvist

Department of Chemistry, Environment and Feed Hygiene, National

Veterinary Institute, SE-751 89 Uppsala, Sweden

e-mail: per.haggblom@sva.se

\section{Introduction}

Fusarium head blight (FHB) is a recurrent disease of wheat, barley, and other small grains across the world, also including northern Europe, mainly caused by the fungal plant pathogens Fusarium graminearum and Fusarium culmorum (Bottalico and Perrone 2002). FHB results not only in the premature bleaching of the spikes giving rise to white or pink kernels and lowered grain yields but also in the accumulation of mycotoxins (van der Fels-Klerx et al. 2012). F. graminearum and F. culmorum are also the causal species for the formation of deoxynivalenol (DON) and its acetylated derivatives, as well as other trichothecenes also including the estrogenic mycotoxin zearalenone (ZEN) (Rodrigues and Naehrer 2012; Tiemann and Dänicke 2007).

The FHB disease cycle starts with the germination of overwintering chlamydospores or mycelia in soil or crop residues, giving rise to the primary inoculum in the spring. The ascospores and/or conidia are then released from the perithecia and are spread by wind or splashing water. When fungal spores land on developing spikes at the time of flowering particularly during moist and warm weather conditions, spore germination and infection of the plant may occur. The considered monocyclic nature of FHB is thought to limit the infection to the primary inoculum released during spring (Wegulo 2012).

However, despite substantial knowledge about the pathogenicity of this plant disease, the present intervention strategies seem to have limited effects on disease mitigation and subsequent accumulation of mycotoxins (van der Fels-Klerx et al. 2012).

Infections by Fusarium sp. and DON accumulation in cereals were reported in spindles, glumes, stems, and leaves of the plant, raising the question of systemic fungal growth 
following FHB infection being responsible for the mycotoxin accumulation (Brinkmeyer et al. 2006; Cowger and Arellano 2013). Several field and experimental studies have shown a positive correlation between DON levels in wheat kernels and the amount of $F$. graminearum DNA (Wegulo 2012). Other studies have shown no colonization of $F$. graminearum or F. culmorum in wheat heads despite high DON levels following inoculation of seeds or crowns. Recently, Moretti et al. (2014) in growth chamber experiments showed that F. graminearum, inoculated in soil or seeds, can grow systemically in the plant with the exception of kernels and heads. High levels of DON and $F$. graminearum DNA were found in crowns, stems, and straw in contrast to low levels of DON and no fungal DNA in the heads and kernels. Ludewig et al. (2005), following ear infection of spring wheat with $F$. graminearum, showed the DON content of kernels to be less than detected in rachis and straw.

Another factor which may influence the distribution of DON in plant tissues is the water solubility of DON. Several studies have demonstrated translocation of the toxin in the sieve tubes via the xylem or phloem (Kang and Buchenauer 1999; Snijders 2004).

In the last years, different Fusarium species infected common cereals particularly in the western part of Sweden and resulted in serious challenges for the cereal and pig industry because of reduced yield and mycotoxin accumulation (Fredlund et al. 2013; Lindblad et al. 2013). DON-producing mold species such as $F$. graminearum and $F$. culmorum were shown to be present, and DON was frequently reported in oats and other cereals.

In a recent survey, we sampled cereals and straw at Swedish pig farms and analyzed for DON, ZEN, T-2, and HT-2 toxin (Nordkvist and Haggblom 2014). The data revealed that DON was almost ubiquitous with $89 \%$ of the samples being contaminated, while ZEN was detected in $54 \%$ of the samples where oats were the cereal grain most frequently contaminated. Higher DON and ZEN concentrations were detected in straw compared to grain harvested in 2011 and 2012. The results clearly indicated straw to be a significant source of DON and ZEN in addition to cereals, however, with large variations between farms.

Trichothecenes have a multitude of effects on eukaryotic cells where the most important seems to be inhibition of protein synthesis (Pinton et al. 2012). Also, DON was shown to inhibit the absorption of nutrients by human epithelial cells "in vitro" (Maresca et al. 2002). Clinical symptoms of trichothecene exposure in animals include feed refusal and weight loss, hemorrhage, emesis, and necrosis of different tissues (Mostrom and Raisbeck 2007). Pigs seem to be the most sensitive animal species to both DON and ZEN exposure from the feed (D’Mello et al. 1999; Dänicke et al. 2004).

In 20-30-kg pigs, the intake of wheat straw was on average $13 \%$ of the diet (van Barneveld 2003), while it was estimated that gestating sows, which are fed restrictively, most likely consume larger amounts. In a recent study, the bioavailability of DON from wheat straw and chaff was investigated in pigs (Rohweder et al. 2013). By measuring the serum concentration of DON, the results clearly indicated that the bioavailability was not affected significantly by feeding straw or a grain matrix.

Clearly, the intake of DON and ZEN from straw may significantly contribute to the mycotoxin exposure in pigs and there will be an increased risk of an exposure exceeding acceptable levels when both the grain and straw are contaminated.

The complexity of Fusarium mycotoxin exposure in man and animals is further complicated by the fact that plants are able to modify the mycotoxins into masked mycotoxins, i.e., not extracted by conventional extraction solvents used in the analyses (Berthiller et al. 2005). The possible hydrolysis of masked mycotoxins, which may be present in high amounts during mammalian digestion, raises concern that the parent toxin may be released and absorbed in the intestines and thus contributes to the exposure. In a recent report, a nearly complete hydrolysis of deoxynivalenol-3- $\beta$-D-glucoside in the intestinal tract of pigs was observed (Nagl et al. 2014).

For animal welfare reasons, straw is commonly used as bedding material in animal production and access to straw in the pig production is laid down in the Swedish animal welfare regulation (SJVFS 2010:15) where attention is being paid to the amount as well as the hygienic quality of the bedding material.

Because of the documented DON and ZEN contamination of straw, there is a need for practical sampling methods that can be used at pig farms in order to select straw which present no mycotoxin harm to the animals. The fact that sampling is generally conceived as a step of the analytical chain which gives the largest contribution to the measurement uncertainty (Reiter et al. 2011) further emphasizes the development of suitable sampling methods. The sampling uncertainty may be even more pronounced for forages and straw than for grains because of irregular shape, density, and the different anatomical fractions of the plant as opposed to grain being more uniform.

In sampling of forages, two strategies to obtain a large number of incremental samples were reported, namely manual grab sampling (Grimsbo Jewett et al. 2001) and core sampling by drilling into the bales (Schaeffer et al. 2000). In the present study, core sampling was applied to big bales of cereal straw directly after harvest.

The aims of the present study were to (a) study the occurrence of DON and $\mathrm{ZEN}$ and the presence of $F$. graminearum and $F$. culmorum in straw bales from wheat, barley, and oats at different pig farms and (b) develop a practical sampling method that could be used at the farm to prevent the use of bedding material with elevated mycotoxin levels that may affect pig health. 


\section{Materials and methods}

The 2013 growing season was characterized by less rainfall and higher temperatures compared to both 2011 and 2012 which coincided with a smaller number of reports indicating elevated DON levels from the pre-harvest surveillance in cereals organized by the Swedish grain industry. For that reason, the identification of possible fields suitable for the straw sampling study was based on previous surveillance data for DON from 2011 to 2012.

Suitable fields were localized by collecting 30 to 40 heads by hand from 17 fields in July or August 1 to 2 weeks prior to harvest, respectively. Samples of wheat (spring and winter varieties), triticale, barley, and oats from the southern (county of Skåne) and western (county of Värmland) regions of Sweden were collected. The grains were recovered by manual threshing and dried at room temperature, ground in a shearing mill (Laboratory Mill 3610, Perten Instruments, Sweden), and analyzed for DON following the procedure by the supplier of the lateral flow device Rida ${ }^{\circledR}$ Quick DON (R-Biopharm AG, Darmstadt) within 2 to 3 days.

Fields where DON was detected in kernels prior to harvest in the county of Värmland were selected for the straw sampling. The fields were harvested by a combine harvester, and straw was subsequently pressed in round or square big bales within 2-3 days according to the normal practice of the farmer. Sampling was carried out in late August to mid-September of bales (approximately $150-350 \mathrm{~kg} / \mathrm{bale}$ ) from fields of winter wheat (45 round bales), barley ( 27 square bales), and oats (18 round bales) within 2 days after baling, respectively. The round bales were $1.2 \mathrm{~m}$ wide with a diameter of 1.2-1.4 m, and the square bales were $0.8 \times 0.9 \times 2.5 \mathrm{~m}$. In addition, 7 round bales of oat straw, from one field in the same region, were sampled inside a shelter after 2 weeks of storage.

The straw samples were collected using a "hay probe bale sampler" sampling probe, 18 -mm diameter $\times 550$-mm length (Best Harvest, Largo, FL, USA), powered by an 18-V cordless electric drill. The sampling of round bales was carried out by drilling twice radially $550 \mathrm{~mm}$ into the bale, and the straw was mixed to 15 - to 30 -g dry matter samples. Accordingly, square bales were sampled by drilling once from each short side of the bale. The water content of the samples was estimated after drying at $60{ }^{\circ} \mathrm{C}$ overnight $(16 \mathrm{~h})$ in a ventilated drying cupboard. All samples were ground on a hammer mill to pass a 1-mm screen before analysis of mycotoxins. The ground samples were stored at room temperature prior to mycotoxin and DNA analysis. The analyses of DON and ZEN were carried out by ELISA (Ridascreen ${ }^{\circledR}$ DON and zearalenone, respectively, R-Biopharm AG, Darmstadt). Limits of detection (LOD) and limits of quantification (LOQ) were 37 and $110 \mu \mathrm{g} / \mathrm{kg}$ for DON and 3.5 and $10.5 \mu \mathrm{g} / \mathrm{kg}$ for ZEN, respectively. Mycotoxin concentrations exceeding the range of the calibration curve (DON $500 \mu \mathrm{g} / \mathrm{kg}$, ZEN $280 \mu \mathrm{g} / \mathrm{kg}$ ) were diluted accordingly.
A subset of seven samples of wheat straw, five samples of barley straw, and eight samples of oat straw were selected to cover the range of DON and ZEN concentrations and were subject to specific DNA analysis for quantification of $F$. graminearum and F. culmorum. Before analyses, the samples were further homogenized by pestle and mortar using liquid nitrogen. DNA was extracted and quantified in $0.2 \mathrm{~g}$ straw, in parallel as previously described, using the TaqMan ${ }^{\circledR}$ Exogenous Internal Positive Control (Applied Biosystems, CA, USA) (Fredlund et al. 2008; Fredlund et al. 2013). The internal amplification control was amplified to the same level as the negative control, showing that the DNA extract did not contain inhibitory substances influencing the quantification. The lowest DNA concentration with linear amplification was $9 \mathrm{pg} / \mathrm{mg}$ straw for $F$. graminearum and $15 \mathrm{pg} / \mathrm{mg}$ straw for F. culmorum.

For regression analysis of the DNA data versus the contents of DON and ZEN, respectively, all data was log (10)-transformed. The three ZEN concentrations below the quantification limit were treated as upper level, i.e., $3.5 \mu \mathrm{g} / \mathrm{kg}$.

The different data sets were evaluated by descriptive statistics (mean, median, min, and max values); distribution was studied graphically by the use of histograms. The relationship between contents of DON and DNA from $F$. graminearum was modelled by linear regression after $\log (10)$ transformation. A study of sampling frequency was made on data from the wheat field (about 8 ha). Average estimates of DON content were calculated by random sampling of subsets of 2 to 45 (all) bales from the data set. The procedure was repeated 20 times; mean values and standard errors of the mean (SEM) were calculated and evaluated graphically. All calculations were made with MS Excel.

\section{Results}

Results from the screening study revealed DON concentrations of kernels below the detection limit of the test kit $<500 \mu \mathrm{g} / \mathrm{kg}$ in the county of Skåne and $600-1800 \mu \mathrm{g} / \mathrm{kg}$ in wheat, oats, and barley from the county of Värmland. The latter region was therefore selected for further sampling studies.

The water content of the collected wheat straw samples was between 37 and $64 \%$; DON was detected in all samples (Fig. 1a) with an average DON concentration of $976 \mu \mathrm{g} / \mathrm{kg}$ and a median of $525 \mu \mathrm{g} / \mathrm{kg}$, while in four bales, the concentrations were above $3000 \mu \mathrm{g} / \mathrm{kg}$. For ZEN, eight samples were below the detection limit; however, the concentrations were more uniform compared to corresponding DON data with an average concentration of $11 \mu \mathrm{g} / \mathrm{kg}$ and a median of $13 \mu \mathrm{g} / \mathrm{kg}$ (Fig. 1b).

The samples from the barley straw bales contained $18-33 \%$ water and were all positive for DON with an average 

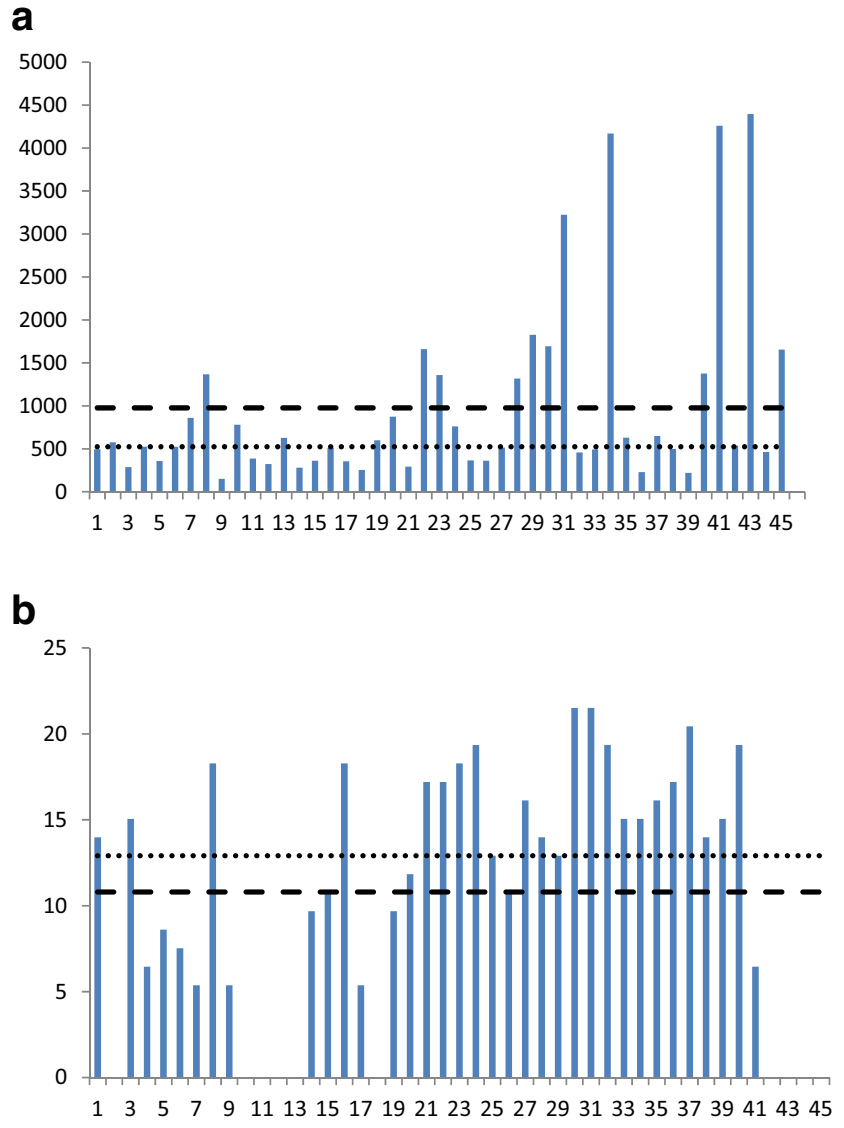

Fig. 1 a Deoxynivalenol $(\mathrm{DON})$ content $(\mu \mathrm{g} / \mathrm{kg})$ in individual straw bales from one field ( $8 \mathrm{ha}$ ) of winter wheat. Average content is shown as a dashed line and median value is represented by a dotted line. $\mathbf{b}$ Zearalenone (ZEN) content $(\mu \mathrm{g} / \mathrm{kg})$ in individual straw bales from one field ( $8 \mathrm{ha}$ ) of winter wheat. Average content is shown as a dashed line and the median value is represented by a dotted line

concentration of $449 \mu \mathrm{g} / \mathrm{kg}$, and three bales contained levels above $800 \mu \mathrm{g} / \mathrm{kg}$ (Fig. 2a). ZEN was detected in three bales with one sample above $100 \mu \mathrm{g} / \mathrm{kg}$ (Fig. 2b).

In the oat straw samples, the water content was between 17 and $23 \%$ and the average DON concentration was $6719 \mu \mathrm{g} /$ $\mathrm{kg}$ (median $6841 \mu \mathrm{g} / \mathrm{kg}$ ), with the lowest concentration at $2614 \mu \mathrm{g} / \mathrm{kg}$ and eight samples above $8000 \mu \mathrm{g} / \mathrm{kg}$ (Fig. 3a). ZEN contamination was detected in all bales with an average concentration of $53 \mu \mathrm{g} / \mathrm{kg}$ with the highest concentration at $219 \mu \mathrm{g} / \mathrm{kg}$ (Fig. 3b). In the stored oat bales, the water content was $13-14 \%$ and 5 out of 7 bales were above 15 , $000 \mu \mathrm{g} \mathrm{DON} / \mathrm{kg}$ with an average concentration of 16 , $382 \mu \mathrm{g} / \mathrm{kg}$ (data not shown). ZEN concentrations in the oat bales were on average $153 \mu \mathrm{g} / \mathrm{kg}$ with a maximum of $284 \mu \mathrm{g} /$ $\mathrm{kg}$ and a minimum at $69 \mu \mathrm{g} / \mathrm{kg}$ (data not shown). In Fig. 4, sampling frequency is related to sampling uncertainty expressed as SEM. It can be seen that sampling only 2 bales at random from the field results in a very high sampling uncertainty. Sampling 5 bales would reduce this uncertainty with about $50 \%$.
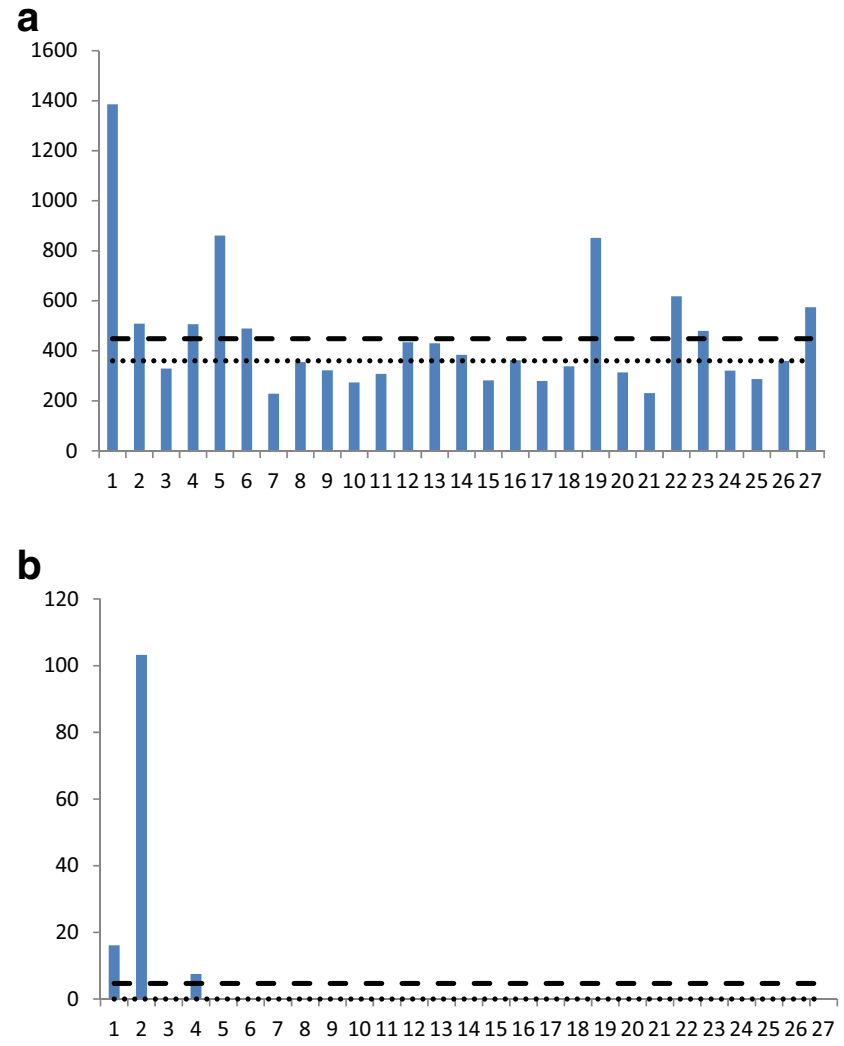

Fig. 2 a Deoxynivalenol (DON) content $(\mu \mathrm{g} / \mathrm{kg})$ in individual straw bales from one field ( $8 \mathrm{ha}$ ) of barley. Average content is shown as a dashed line and the median value is represented by a dotted line. $\mathbf{b}$ Zearalenone $(\mathrm{ZEN})$ content $(\mu \mathrm{g} / \mathrm{kg})$ in individual straw bales from one field ( 8 ha) of barley. Average content is shown as a dashed line and the median value is represented by a dotted line

F. graminearum DNA was present at levels above LOQ in all investigated samples of wheat straw except one, while F. culmorum DNA was detected at levels above LOQ in two samples. Levels of $F$. graminearum DNA were higher in oat straw (max $6444 \mathrm{pg} D N A / m g$ straw) compared to wheat and barley. The analyses of DON/ZEN levels and $F$. graminearum DNA levels showed that the mycotoxin levels were significantly correlated with F. graminearum DNA (Fig. 5).

\section{Discussion}

The results of the present field study support previous information that DON and ZEN may be present in straw (Nordkvist and Haggblom 2014; Brinkmeyer et al. 2006; Dänicke et al. 2006) even at high levels despite good agricultural practice during the growing and harvest seasons. Interestingly, none of the pig farmers taking part in the study had made observations of FHB - symptoms in their crops and the harvested straw were judged suitable for bedding material.

The water content of the oat straw samples was the lowest followed by barley and winter wheat straw. Because the 

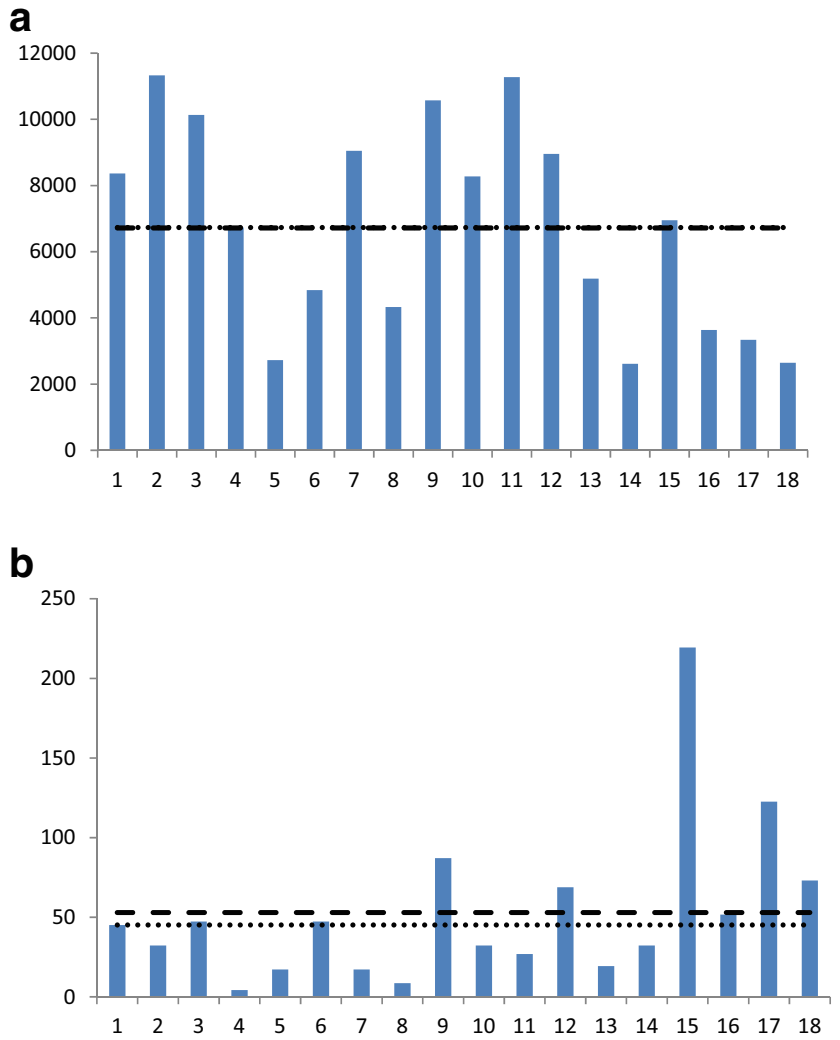

Fig. 3 a Deoxynivalenol (DON) content $(\mu \mathrm{g} / \mathrm{kg})$ in individual straw bales from one field ( $5 \mathrm{ha}$ ) of oats. Average content is shown as a dashed line and the median value is represented by a dotted line. $\mathbf{b}$ Zearalenone $(\mathrm{ZEN})$ content $(\mu \mathrm{g} / \mathrm{kg})$ in individual straw bales from one field (5 ha) of oats. Average content is shown as a dashed line and the median value is represented by a dotted line

sampling was carried out only a few days after harvest, except for the stored oat straw, it suggests that the measured straw concentrations of mycotoxins were most likely present at the time of harvest. In experimental studies, Rohweder et al. (2011) observed decreased DON levels and increased ZEN levels when inoculated straw was stored outdoors for longer

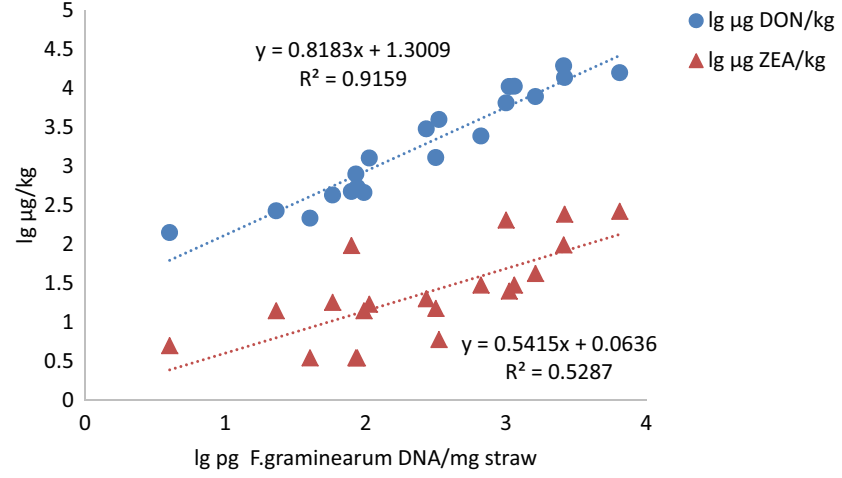

Fig. 5 Regression of DON (filled circles) and ZEN levels (filled triangles) against levels of DNA from $F$. graminearum in straw from winter wheat, barley, and oats $(n=20)$

periods. No kernel contamination in the collected straw samples was observed.

The uneven distribution of mycotoxins in the straw bales from some fields indicated large variations in fungal infections within the field. In winter wheat, four bales contained elevated DON levels ( $>4000 \mu \mathrm{g} / \mathrm{kg}$ ) compared to most bales. Interestingly, those bales were from a slightly lower part of the field possibly with a higher moisture level in the soil.

For ZEN, no obvious correlation with the DON data could be seen, and in about $10 \%$ of the samples, the levels were below LOQ. In barley, DON levels were more uniform in the bales in contrast to ZEN where three samples were above LOQ and one sample above $100 \mu \mathrm{g} / \mathrm{kg}$.

In contrast to bales from other cereals, the DON and ZEN levels in oats were higher and also the distribution of mycotoxins in oats seemed to be more uniform. Again, the levels of mycotoxins could vary a lot between individual bales with no obvious correlation between DON and ZEN levels, making the sampling rather difficult.

Results from the present field study did not reveal which part of the straw that may harbor mycotoxins at the time of harvest. In experimental studies where winter wheat was
Fig. 4 Sampling frequency related to number of sampled bales. Population grand average and median are plotted at respective DON levels (see Fig. 1a)

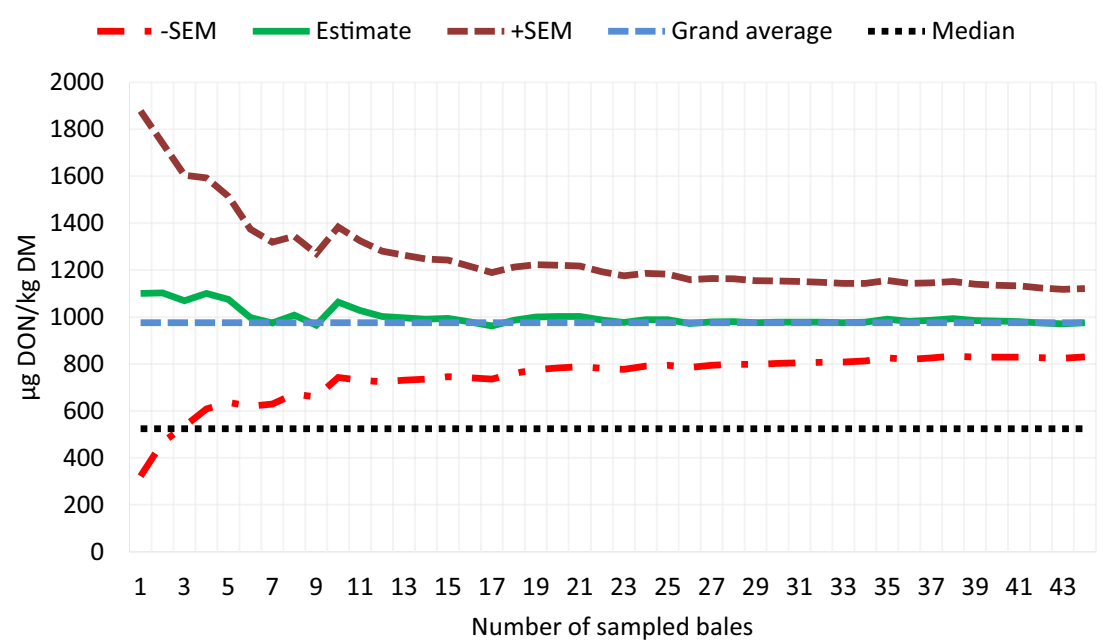


inoculated with spores of F. culmorum, the mean DON and ZEN concentrations were, however, shown to be significantly higher in glumes and spindles compared to the straw (Brinkmeyer et al. 2006). Further studies should reveal if glumes and spike tissues are the main sources of DON and ZEN in the straw also under field conditions.

Several studies have shown that the amount of DON produced by $F$. graminearum in grain is positively correlated with fungal biomass (Demeke et al. 2010). Other field studies have also shown a positive linear relationship between DON concentrations and the FHB intensity as reviewed in Wegulo (2012).

Results of specific F. graminearum DNA showed extensive fungal growth in straw from all tested cereals with the highest concentrations in oats, suggesting a correlation between the amounts of fungal hyphae in the plant and DON levels. When comparing the results in the present study with the data from Fredlund et al. (2013) and Lindblad et al. (2013), considerably higher levels of $F$. graminearum-specific DNA were detected in straw compared to the kernels. In the present study, the range of $F$. graminearum DNA concentrations in oat straw was between 661 and $6444 \mathrm{pg} / \mathrm{mg}$ compared to the range in oat kernels of 4-74 and 9-17 pg/mg in 2010 and 2011 , respectively. The results clearly suggest a massive fungal colonization in other segments of the plant but the kernel. The results also demonstrate that at the time of harvest, Fusarium-infected straw and chaff represent a great risk for spreading $F$. graminearum inoculum to the soil until the next growing season.

Whether the demonstrated straw colonization by $F$. graminearum was the result of the mold being present in the soil or the seeds or infections during flowering is difficult to find out because of diverging reports (Ludewig et al. 2005; Wegulo 2012; Moretti et al. 2014). The farmers participating in the study were all using seeds produced on the farm which may have influenced the infection.

In the present study, four fields were studied to give a rationale for a recommended procedure to be used in practical straw sampling and commercially available equipment designed for sampling of forages was used. Sampling of individual bales on the respective fields made it possible to get information of the in-field variation of the DON and ZEN contamination as the degree of heterogeneity has a great impact on the sampling plan. The use of drilled core sampling has two main advantages, a core sample collected from a cross section of a big bale represents a large proportion of the bale and, secondly, the sample is cut into short pieces that allows for immediate grinding without further preparation of the sample. In the review by Miraglia et al. (2005), it was pointed out that following the sampling variance, the "sample preparation variance" (resulting from subsampling and grinding of the collected (aggregate) sample) was the most significant contributor to the total analytical variation. Thus, grinding the total sampled material will reduce the analytical variation.
In the wheat field, 45 bales were sampled and the distribution was very heterogeneous, as illustrated in Fig. 1a. Half of the bales had a DON content less than $525 \mu \mathrm{g} / \mathrm{kg}$, while the average content $(976 \mu \mathrm{g} / \mathrm{kg})$ was strongly influenced by four highly contaminated bales. Miraglia et al. (2005) concluded that sampling variance "increases with lowering of the toxin concentration" which is in agreement with the findings in the present work where mean DON level was lower in wheat and barley straw compared to oat straw. For wheat and barley straw, the mean and median values of DON differed greatly with the mean greater than median, reflecting a strong deviation from the normal distribution. It also implies that the average may be of limited use for describing the degree of contamination of individual bales and thus for risk assessment of animal exposure to DON. The more highly contaminated oat straw was less heterogeneous, but still the DON content varied fourfold between the lowest and highest concentrations within one field. A calculation of sampling uncertainty was made for the wheat field. In Fig. 4, the estimates of DON content based on different numbers of sampled bales are shown, where it can be seen that, for this field, sampling 5 bales will result in acceptable sampling uncertainty. However, an estimated mean value of about $1000 \mathrm{DON} \mu \mathrm{g} / \mathrm{kg}$ does not imply the absence of highly contaminated individual bales.

Also, the ZEN content of straw varied a lot even if mean and median values were close within the 45 bales of wheat; the distribution was far from normal with $<\mathrm{LOQ}(3.5 \mu \mathrm{g} / \mathrm{kg})$ as mode. In the barley field, the contamination was found to be the lowest where the toxin was distributed in three out of 27 bales, giving an average contamination of $5 \mu \mathrm{g} / \mathrm{kg}$ while the median remained at $<$ LOQ.

Additional exposure to DON and ZEN from straw, when used as bedding material, cannot be excluded in pig production particularly as the bioavailability of DON for pigs was shown to be similar to the availability from kernels (Rohweder et al. 2013). The significance of mycotoxin exposure from straw at pig farms with cereal production should for those reasons not be neglected particularly in years when high levels of DON and ZEN are also detected in the feed grain. The present study has demonstrated that estimating the concentrations of DON and ZEN in straw requires a careful sampling plan. However, with a limited number of samples, preferably using a sampling probe, it is possible to distinguish lots of straw that should not be used as bedding material for pigs.

Acknowledgments We thank the Swedish Farmer's Foundation for Agricultural Research for a generous financial support. We also want to express our gratitude to the farmers participating in the study as well as the pre-harvest surveillance network organized by the Swedish grain industry. Analyses of mycotoxins were skillfully performed by Anna Stepinska, Maria Agnedal, and Galina Ganchenko. The DNA work was generously carried out by the National Food Administration (Dr. Elisabeth Fredlund), Uppsala, Sweden. 


\section{Conflict of interest None}

Open Access This article is distributed under the terms of the Creative Commons Attribution License which permits any use, distribution, and reproduction in any medium, provided the original author(s) and the source are credited.

\section{References}

Berthiller F, Schumacher R, Buttinger G, Krska R (2005) Rapid simultaneous determination of major type A- and B-trichothecenes as well as zearalenone in maize by high performance liquid chromatography-tandem mass spectrometry. J Chromatogr 1062: 209-216

Bottalico A, Perrone G (2002) Fusarium species and mycotoxins associated with the head blight in small-grain cereals in Europe. Eur J Plant Pathol 108:611-624

Brinkmeyer U, Dänicke S, Lehmann M, Valenta H, Lebzien P, Schollenberger M (2006) Influence of a Fusarium culmorum inoculation of wheat on the progression of mycotoxin accumulation, ingredient concentrations and ruminal in sacco dry matter degradation of wheat residues. Arch Anim Nutr 60:141-157

Cowger C, Arellano C (2013) Fusarium graminearum infection and deoxynivalenol concentrations during development of wheat spikes. Phytopathology 103:460-471

Dänicke S, Valenta H, Doll S (2004) On the toxicokinetics and the metabolism of deoxynivalenol (DON) in the pig. Arch Anim Nutr 58: $169-180$

Dänicke S, Lehmann M, Valenta H, Lebzien P, Schollenberger M, Südekum KH, Weinert J, Flachowsky G (2006) Influence of a Fusarium culmorum inoculation of wheat on the progression of mycotoxin accumulation, ingredient concentrations and ruminal in sacco dry matter degradation of wheat residues. Arch Anim Nutr 60: $141-157$

Demeke T, Gräfenhan T, Clear RM, Phan A, Ratnayaka I, Chapados J, Patrick SK, Gaba D, Lévesque A, Seifert KA (2010) Development of a specific TaqMan ${ }^{\circledR}$ real-time PCR assay for quantification of Fusarium graminearum clade 7 and comparison of fungal biomass determined by PCR with deoxynivalenol content in wheat and barley. Int J Food Microbiol 141:45-50

D’Mello JPF, Placinta CM, Mac Donald AMC (1999) Fusarium mycotoxins: a review of global implications for animal health, welfare and productivity. Anim Feed Sci Technol 80:183-205

Fredlund E, Gidlund A, Olsen M, Börjesson T, Spliid NH, Simonsson M (2008) Method evaluation of Fusarium DNA extraction from mycelia and wheat for down-stream real-time PCR quantification and correlation to mycotoxin levels. J Microbiol Methods 73:33-40

Fredlund E, Gidlund A, Sulyok M, Börjesson T, Krska R, Olsen M, Lindblad M (2013) Deoxynivalenol and other selected Fusarium toxins in Swedish oats-occurrence and correlation to specific Fusarium species. Int J Food Microbiol 167:276-283

Grimsbo Jewett J, Schaeffer CR, Moon RD, Lamb JFS (2001) Field sampling strategies for studies of alfalfa forage quality. Can J Plant Sci 81:703-712

Kang Z, Buchenauer H (1999) Studies on the infection process of Fusarium culmorum in wheat spikes: degradation of host cell wall components and localization of trichothecene toxins in infected tissue. Eur J Plant Pathol 108:653-660

Lindblad M, Gidlund A, Sulyok M, Börjesson T, Krska R, Olsen M et al (2013) Deoxynivalenol and other selected Fusarium toxins in Swedish wheat-occurrence and correlation to specific Fusarium species. Int J Food Microbiol 167:284-291
Ludewig A, Kabsch U, Verreet JA (2005) Comparative deoxynivalenol accumulation and aggressiveness of isolates of Fusarium graminearum on wheat and the influence on yield as affected by fungal isolate and wheat cultivar. J Plant Dis Prot 112:329-342

Maresca M, Mahfoud R, Garmy N, Fantini J (2002) The mycotoxin deoxynivalenol affects nutrient absorption in human intestinal epithelial cells. J Nutr 132:2723-2731

Miraglia M, De Santis B, Minardi V, Debegnach F, Brera C (2005) The role of sampling in mycotoxin contamination: an holistic view. Food Addit Contam: Part A 22:31-36

Moretti A, Panzarini G, Somma S, Campagna C, Ravaglia S, Logrieco AF, Solfrizzo M (2014) Systemic growth of $F$. graminearum in wheat plants and related accumulation of deoxynivalenol. Toxins 6:1308-1324

Mostrom MS, Raisbeck MF (2007). In: Gupta RC (ed) Veterinary toxicology. Elsevier, New York, 951-976

Nagl V, Woechtl B, Schwartz-Zimmerman HE, Hennig-Pauka I, Moll WD, Adam G, Berthiller F (2014) Metabolism of the masked mycotoxin deoxynivalenol-3-glucoside in pigs. Toxicol Lett 229:190197

Nordkvist E, Haggblom P (2014) Fusarium mycotoxin contamination of cereals and bedding straw at Swedish pig farms. Feed Sci Technol 198:231-237

Pinton P, Tsybulskyy D, Lucioli J, Callu P, Lyazhri F, Grosjean F, Bracarense AP, Kolf-Clauwand M, Oswald IP (2012) Toxicity of deoxynivalenol and its acetylated derivatives on the intestine: differential effects on morphology, barrier function, tight junction proteins and MAPKinases. Toxicol Sci 130:180-190

Reiter EV, Dutton MF, Agus A, Nordkvist E, Mwanza MF, Njobeh PB, Prawano D, Häggblom P, Razzazi-Fazeli E, Zentek J, Andersson MG (2011) Uncertainty from sampling in measurements of aflatoxins in animal feedingstuffs: application of the Eurachem/ CITAC guidelines. Analyst 136:4059-4069

Rodrigues I, Naehrer K (2012) A three-year survey on the worldwide occurrence of mycotoxins in feedstuffs and feed. Toxins 4:663-675

Rohweder D, Valenta H, Sondermann S, Drochner W, Pahlow G, Döll S, Dänicke S (2011) Effect of different storage conditions on the mycotoxins contamination of Fusarium culmorum-infected and noninfected wheat straw. Mycotoxin Res 27:145-153

Rohweder D, Kersten S, Valenta H, Sonnermann S, Schollenberger M, Drochner W, Dänicke S (2013) Bioavailability of the Fusarium toxin deoxynivalenol (DON) from wheat straw and chaff in pigs. Arch Anim Nutr 67:37-47

Schaeffer CC, Martin NP, Grimsbo Jewett J, Halgerson J, Moon RD, Cuomo GR (2000) Sampling requirements for forage quality characterization of rectangular hay bales. Agron J 92:64-68

SJVFS (2010) 15 Föreskrifter och allmänna råd om djurhållning inom lantbruket m.m.(Swedish domestic legislation, in Swedish)

Snijders CHA (2004) Resistance in wheat to Fusarium infection and trichothecene formation. Toxicol Lett 153:37-46

Tiemann U, Dänicke S (2007) In vivo and in vitro effects on the mycotoxins zearalenone and deoxynivalenol on different nonreproductive and reproductive organs in female pigs: a review. Food Addit Contam 24:306-314

van Barneveld R (2003) Accurate assessment of diet intake and composition in various pig housing systems. Pig Research Institute, Australian pork Limited (Project 1754)

Van der Fels-Klerx HJ, Klemsdal S, Hietaniemi V, Lindblad M, IoannouKakouriand I, Van Asselt ED (2012) Mycotoxin contamination of cereal grain commodities in relation to climate in North West Europe. Food Addit Contam 29:1581-1592

Wegulo SN (2012) Factors influencing deoxynivalenol accumulation in small grain cereals. Toxins 4:1157-1180 